\title{
O ensino de Ciências da Natureza nos anos inicias do Ensino Fundamental
}

\author{
The teaching of Natural Sciences in the early years of Elementary School \\ La enseñanza de las Ciencias Naturales en los primeros años de la Escuela Primaria
}

Recebido: 18/11/2021 | Revisado: 24/11/2021 | Aceito: 25/11/2021 | Publicado: 25/11/2021

\author{
Érica Vitória Santos Silva \\ ORCID: https://orcid.org/0000-0003-1480-7924 \\ Faculdade Guaraí, Brasil \\ E-mail: ericavitoriasantos20@gmail.com \\ Sheylla Pereira Melo \\ ORCID: https://orcid.org/0000-0002-8936-9247 \\ Faculdade Guaraí, Brasil \\ E-mail: sheyllamelo35@gmail.com \\ Aluísio Vasconcelos de Carvalho \\ ORCID: https://orcid.org/0000-0002-3793-3133 \\ Faculdade Guaraí, Brasil \\ E-mail: aluisiovasconcelos@gmail.com
}

\begin{abstract}
Resumo
O aprendizado das Ciências da Natureza nos Anos Iniciais do Ensino Fundamental é frequentemente uma matéria pendente na vida de nossas salas de aula, pois a maior parte do conhecimento abordado nesta fase sempre começa a partir de uma perspectiva social. É importante levar em consideração a capacidade cognitiva dos alunos para esse tipo de conhecimento abstrato, o conhecimento prévio sobre o assunto e a motivação ao longo do processo de ensinoaprendizagem. Esses fatores determinarão a eficácia ou não do conhecimento adquirido pelos alunos. O objetivo principal foi descrever e analisar as características do ensino de Ciências da Natureza no referido nível de ensino. Este estudo justifica-se pela relevância do nível de escolaridade inicial e do ensino de ciências nessa fase, tendo em conta que inclui crianças numa fase caracterizada pela curiosidade e pelo desejo de conhecer o mundo. Essa justificativa também se apoia no fato de haver pouca informação sobre o ensino de ciências nas séries iniciais do Ensino Fundamental.
\end{abstract}

Palavras-chave: Ensino de ciências da natureza; Anos iniciais; Aprendizagem.

\begin{abstract}
Learning Natural Sciences in the Early Years of Elementary School is often a pending subject in the life of our classrooms, as most of the knowledge covered at this stage always starts from a social perspective. It is important to take into account the cognitive capacity of students for this type of abstract knowledge, prior knowledge about the subject and motivation throughout the teaching-learning process. These factors will determine the effectiveness or not of the knowledge acquired by the students. The main objective was to describe and analyze the characteristics of the teaching of Natural Sciences at that level of education. This study is justified by the relevance of the level of initial education and science teaching at this stage, taking into account that it includes children at a stage characterized by curiosity and the desire to know the world. This justification is also supported by the fact that there is little information about science teaching in the early grades of elementary school.
\end{abstract}

Keywords: Teaching of natural sciences; Early years; Learning.

\section{Resumen}

El aprendizaje de las Ciencias Naturales en los Primeros Años de la Escuela Primaria suele ser una asignatura pendiente en la vida de nuestras aulas, ya que la mayor parte del conocimiento cubierto en esta etapa siempre parte de una perspectiva social. Es importante tener en cuenta la capacidad cognitiva de los estudiantes para este tipo de conocimientos abstractos, los conocimientos previos sobre el tema y la motivación a lo largo del proceso de enseñanzaaprendizaje. Estos factores determinarán la efectividad o no de los conocimientos adquiridos por los estudiantes. El objetivo principal fue describir y analizar las características de la enseñanza de las Ciencias Naturales en ese nivel educativo. Este estudio se justifica por la relevancia del nivel de educación inicial y enseñanza de las ciencias en esta etapa, teniendo en cuenta que incluye a los niños en una etapa caracterizada por la curiosidad y el deseo de conocer el mundo. Esta justificación también está respaldada por el hecho de que hay poca información sobre la enseñanza de las ciencias en los primeros grados de la escuela primaria.

Palabras clave: Didáctica de las ciencias naturales; Primeros años; Aprendiendo. 


\section{Introdução}

De maneira geral, as pesquisas vinculadas ao ensino de Ciências da Natureza na fase dos primeiros anos do Ensino Fundamental são em menor número, segundo os argumentos de Cachapuz et al (2011), devido à escassez de pessoas formadas em ciências e que se dedicam a estudar problemas didáticos na etapa mencionada.

De fato, existem poucos estudos encontrados no país a respeito dos processos ensino e aprendizagem de ciências naturais nos anos iniciais do Ensino Fundamental, sendo ainda menos frequente na esfera privada.

De acordo com os resultados de alguns estudos feitos por autores como Delizoicov, Angotti e Pernambuco (2011), o ensino através de a experimentação é menos frequente em escolas particulares e em um contexto sociocultural crítico. Esses dados também contribuem para a instalação do foco de atenção nas escolas particulares. Da mesma forma, este estudo indica que os recursos nas escolas particulares devem ser compartilhados por menos pares, o que é mais um motivo para enfatizar os recursos educacionais, em termos de descrição, mas também de uso e exploração.

Por um lado, é necessário conhecer as diferentes estratégias de trabalho em sala de aula, pois podem oferecer alternativas aos professores interessados e uma área de reflexão sobre as habilidades promovidas nos alunos. Em contrapartida, pode ser útil ter informações para revelar as necessidades e interesses dos educadores quanto aos recursos utilizados e aos esperados ou desejáveis para melhorar a tarefa.

Esta pesquisa justifica-se, antes de tudo, do ponto de vista pessoal, uma vez que a atual atividade profissional do pesquisador está focada no ensino de Ciências da Natureza nos anos iniciais do Ensino Fundamental.

Em segundo lugar, pelo valor que representa um estudo dessas características; terceiro, devido à relevância da própria educação inicial e à inclusão do ensino de ciências naturais nesse nível de ensino; quarto, pela importância da educação científica; e, finalmente, devido à escassa pesquisa realizada no Brasil na esfera privada.

Da mesma forma, há pouca informação sobre práticas de ensino deste tema no processo ensino-aprendizagem, além de ser um campo muito heterogêneo em termos de metodologias e disponibilidade de recursos educacionais, bem como materiais didáticos.

Entre os professores de Ciências da Natureza, melhorar a prática é o principal objetivo da pesquisa. No entanto, Delizoicov, Angotti e Pernambuco (2011) propõem que muitos desses estudos são limitados ao que funciona na prática; o autor argumenta que o papel da pesquisa não se baseia apenas em mostrar o que funciona.

Nos últimos anos, a "tradição pedagógica" (Silva, 2011, p. 59) na pesquisa educacional teve como seu primeiro objetivo melhorar diretamente a prática, aqui entendida como o ensino de Ciências da Natureza. Mas a realidade das práticas atuais e as dificuldades que apresentam, bem como sua conscientização, foram objeto de alguns dos estudos de pesquisa mais relevantes.

\section{Metodologia}

A teorização da presente pesquisa tem como metodologia a pesquisa teórico-bibliográfica, descritiva, baseada na pesquisa em livros, artigos, revistas, observações e análises sobre o tema abordado. Segundo Demo (2014, p. 20), “a pesquisa teórica não implica imediata intervenção na realidade, mas nem por isso deixa de ser importante, pois seu papel é decisivo na criação de condições para a intervenção". Assim sendo, se baseia em um contexto teórico e seu propósito fundamental consiste em desenvolver uma pesquisa por meio de ampliar generalizações ou princípios já pesquisados.

Entre os achados bibliográficos estão Azevedo (2016), Anlex (2003), Base Nacional Comum Curricular (BNCC) (2019), Cachapuz (2011), Chassot (2018), Demo (2014), Delizoicov, Angoth e Pernambuco (2011), Fabri e Silveira (2013), Geraldo (2014), Hazen e Trefil (2010), Lakimi (2014), Marandino (2009), Morais (1998), Perrenoud (2007), Ribeiro (2011), 
Sasseron (2008), Silva (2011), Souza, Bastos e Angot (2007), Terrazzan e Dutra (2009), Unesco (2008), através de todos estes obteve-se ótimos resultados referente a este tema.

\section{Possibilidades e Desafios do Ensino das Ciências da Natureza}

$\mathrm{O}$ ensino e a aprendizagem das ciências naturais constituem todo um processo de desenvolvimento e amadurecimento no pensamento dos alunos, visam promover discussões concretas que fornecem elementos teóricos e práticos onde se consegue evidenciar relações necessárias e fundamentais entre elementos conceituais, sociais e culturais típicos das ciências naturais.

As Ciências da Natureza correspondem às áreas das Ciência Naturais e foram consideradas como uma unidade composta por Ciências Biológicas, Ciências Físicas e Químicas. Essa escolha ocorreu devido à forma como o conteúdo científico vem sendo estruturado no Ensino Fundamental, não sendo dissociado, como ocorre nos níveis superiores.

De acordo com a Base Nacional Comum Curricular (BNCC) (2017) as competências principais das Ciências da Natureza para o Ensino Fundamental são:

1. Compreender as Ciências da Natureza como empreendimento humano, e o conhecimento científico como provisório, cultural e histórico.

2. Compreender conceitos fundamentais e estruturas explicativas das Ciências da Natureza, bem como dominar processos, práticas e procedimentos da investigação científica, de modo a sentir segurança no debate de questões científicas, tecnológicas, socioambientais e do mundo do trabalho, continuar aprendendo e colaborar para a construção de uma sociedade justa, democrática e inclusiva.

3. Analisar, compreender e explicar características, fenômenos e processos relativos ao mundo natural, social e tecnológico (incluindo o digital), como também as relações que se estabelecem entre eles, exercitando a curiosidade para fazer perguntas, buscar respostas e criar soluções (inclusive tecnológicas) com base nos conhecimentos das Ciências da Natureza.

4. Avaliar aplicações e implicações políticas, socioambientais e culturais da ciência e de suas tecnologias para propor alternativas aos desafios do mundo contemporâneo, incluindo aqueles relativos ao mundo do trabalho.

5. Construir argumentos com base em dados, evidências e informações confiáveis e negociar e defender ideias e pontos de vista que promovam a consciência socioambiental e o respeito a si próprio e ao outro, acolhendo e valorizando a diversidade de indivíduos e de grupos sociais, sem preconceitos de qualquer natureza.

6. Utilizar diferentes linguagens e tecnologias digitais de informação e comunicação para se comunicar, acessar e disseminar informações, produzir conhecimentos e resolver problemas das Ciências da Natureza de forma crítica, significativa, reflexiva e ética.

7. Conhecer, apreciar e cuidar de si, do seu corpo e bem-estar, compreendendo-se na diversidade humana, fazendo-se respeitar e respeitando o outro, recorrendo aos conhecimentos das Ciências da Natureza e às suas tecnologias.

8. Agir pessoal e coletivamente com respeito, autonomia, responsabilidade, flexibilidade, resiliência e determinação, recorrendo aos conhecimentos das Ciências da Natureza para tomar decisões frente a questões científico-tecnológicas e socioambientais e a respeito da saúde individual e coletiva, com base em princípios éticos, democráticos, sustentáveis e solidários.

A criança é curiosa por natureza, seu interesse pelo ambiente a motiva a investigar. De acordo com Cachapuz et al (2011), ela manipula, explora, experimenta, está constantemente fazendo perguntas. Portanto, é necessário manter as luzes acesas da curiosidade e do desejo de saber na criança, e proporcionar um ambiente que estimule essa curiosidade. Sendo assim, as Ciências da Natureza fazem parte deste escopo de curiosidade imanente nas crianças. 
Nas salas de aula é possível encontrar diferentes comportamentos de alunos e professores, que são o resultado das diferentes personalidades dos protagonistas, em combinação com suas histórias, em torno de um conteúdo disciplinar a ser aprendido.

A curiosidade pelas Ciências da Natureza faz parte da vida das crianças; e isso deve ser considerado um desafio, mas ao mesmo tempo uma oportunidade, para que os professores possam levar em consideração este interesse e melhorar suas habilidades para a aprendizagem.

\subsection{A Educação Científica e o Ensino das Ciências da Natureza}

Segundo o relatório da UNESCO (2008) "Projeto de Consciência para a Sustentabilidade", a sociedade moderna requer formação científica, que melhorará a qualidade de vida de crianças e jovens, bem como seu papel como cidadãos. Esse conceito é reafirmado por Terrazzan e Dutra (2009) ao propor que o nível de desenvolvimento de um país está vinculado ao investimento em ciência e tecnologia e ao fato de existirem cientistas e tecnólogos, que por sua vez são o produto de jovens motivados a seguir essas carreiras.

A declaração de Budapeste - UNESCO (2003), que emerge da "Conferência Mundial de Ciência para o século XXI", destaca o consenso internacional que coloca a educação científica de crianças e jovens como uma prioridade para o desenvolvimento e o bem-estar, tanto das nações individuais, como para o planeta como um todo.

A Declaração enfatiza que ter acesso contínuo à educação, desde a infância, é um direito humano, e que a educação científica é essencial ao desenvolvimento humano. O principal foco da ciência aplicada de hoje deve ser o de reduzir a pobreza e auxiliar a erguer todos os níveis da sociedade mundial a padrões de vida decentes. [...] Um novo compromisso, reforçado e constante, para com a ciência dos países periféricos consiste na maior prioridade para que a ciência seja fortalecida, podendo assim contribuir para um desenvolvimento humano auto-sustentável e para a expansão da cultura (UNESCO, 2003, p. 7-8).

Após esse desenvolvimento, Chassot (2018) considera a alfabetização científica como uma meta a priorizar quando se fala em educação básica para todas as pessoas.

O conceito de alfabetização científica é complexo e complementado pelo de "culturalização científica", destacado no relatório da UNESCO (2008) sobre ações educativas em Ciência e Tecnologia na educação formal e não formal. Destaca a importância de os alunos saberem como a ciência é pensada e feita. Ensiná-lo nos permite apreciar essa cultura fornecendo a eles ferramentas para resolver problemas da vida cotidiana e desenvolver habilidades de pensamento de ordem superior, como pensamento hipotético, criativo, inferencial, divergente, crítico-reflexivo e metacognitivo.

Para Chassot (2018), a alfabetização científica é a finalidade mais importante do ensino de Ciências; estas razões se baseiam em benefícios práticos pessoais, práticos sociais, para a própria cultura e para a humanidade, os quais se obtêm por meio da combinação de duas escalas binárias: individual/coletivo e prática/conceitual, dando lugar aos quatro domínios indicados.

Além disso, o relatório UNESCO (2008) propõe uma série de recomendações destinadas a promover a alfabetização científica básica, de acordo com as demandas da sociedade atual.

Antes de investigar o que diferentes autores contribuem nesse sentido, é necessário explicar o que se entende por ciências naturais. As ciências da natureza ou ciências naturais abrangem todas as disciplinas científicas dedicadas ao estudo da natureza. Elas são responsáveis pelos aspectos físicos da realidade, diferentemente das ciências sociais que estudam os fatores humanos. Podem ser mencionados cinco grandes ramos das ciências naturais: Biologia, Física, Química, Geologia e Astronomia.

De acordo com Chassot (2018), se refletirmos sobre como a abordagem nas salas de aula evoluiu historicamente, é possível perceber que nas décadas de sessenta e setenta a preocupação curricular se concentrava na apropriação do conhecimento científico para trazer essas teorias para mais perto das crianças e com a pesquisa como um processo, enquanto nos anos oitenta e noventa essas preocupações mudaram para incluir aspectos diferentes. 
Entre essas interpretações, destacam-se as tendências à mudança no cotidiano, relacionando a ciência aos aspectos sociais e tecnológicos, desenvolvendo a alfabetização científica no contexto da cidadania ativa e responsável, promovendo a ciência como fenômeno cultural, garantindo que a ciência seja mais orientada para as pessoas e considere o conhecimento e as experiências anteriores dos alunos. Também é importante gerenciar as atividades de solução de problemas para desenvolver a criatividade e incentivar a tomada de decisões e as habilidades sociais, além de facilitar o fortalecimento da autoestima dos alunos.

Além das dificuldades de definir o que e como ensinar o conteúdo, acompanhando Chassot (2018, p. 79), vale destacar a concepção que os professores têm sobre a ciência: "se a mesma é concebida como objetiva e válida, é provável observar professores que preferem aplicar métodos e fórmulas, assim como transmitir "verdades" científicas".

Segundo Lakomy (2014), a partir dessa abordagem, se privilegia a observação e a experimentação, e se atribui à pobreza nos resultados e à falta de recursos ou a realização de poucos experimentos, mas a estratégia em si raramente é questionada.

O desafio de como ensinar indica dois grandes núcleos rígidos: por um lado, a necessidade de os professores se conscientizarem do que fazem e por que fazem; e, por outro, entender que o conteúdo a ser ensinado deve ser incluído na finalidade da ciência escolar, de acordo com os objetivos e particularidades dos alunos que aprendem.

Continuando com a análise das abordagens adotadas pelos professores de ciências ao longo do tempo, Ribeiro (2011) detalha em seu livro "História da educação brasileira", as diferentes metodologias aplicadas, os conhecimentos privilegiados em cada uma, bem como os celulares para selecionar e organizar o currículo e as estratégias de ensino. Por fim, o autor explica os obstáculos apresentados por cada uma dessas abordagens.

Ribeiro (2011) salienta que, à medida que o foco se afasta do ensino tradicional e se orienta em direção de modelos e pesquisa direcionada, os professores são muito exigentes em termos de planejamento, conhecimentos necessários e tempo. Da mesma forma, o ensino tradicional acaba frustrando os professores e causando desconexão entre os interesses dos alunos e conteúdos que são realmente refletidos em sala de aula. Também marca as dificuldades do ensino por descobertas, ao equiparar a maneira como estudantes e cientistas aprendem, esquecendo que a motivação do aluno nessas circunstâncias só é alimentada se os resultados forem positivos. 
Tabela 1: Características de algumas abordagens ao ensino de Ciências da Natureza.

\begin{tabular}{|c|c|}
\hline \multicolumn{2}{|l|}{ Ensino tradicional } \\
\hline $\begin{array}{l}\text { Pressupostos e objetivos da } \\
\text { educação científica }\end{array}$ & $\begin{array}{l}\text { O conhecimento científico é assumido como conhecimento absoluto. A ciência nos permite saber o que a } \\
\text { natureza realmente é. } \\
\text { Aprender ciência é aprender o que os cientistas sabem sobre natureza, reproduzindo-a o mais fielmente } \\
\text { possível. } \\
\text { A formação de professores é baseada na apresentação dos últimos avanços científicos. }\end{array}$ \\
\hline $\begin{array}{l}\text { Critérios para selecionar e } \\
\text { organizar o conteúdo }\end{array}$ & $\begin{array}{l}\text { Baseado em conhecimento disciplinar. São os conhecimentos aceitos pela comunidade científica. O que foi } \\
\text { aprendido é ensinado como foi aprendido. Os conhecimentos são apresentados como saberes acabados. } \\
\text { Uma visão estática e absoluta do saber científico é transferida para os alunos. As teorias que já foram } \\
\text { superadas não são ensinadas ou apresentadas como conhecimentos abandonados. }\end{array}$ \\
\hline $\begin{array}{l}\text { Atividades de } \\
\text { ensino/avaliação }\end{array}$ & $\begin{array}{l}\text { Transmitem-se conhecimentos verbais. O professor dirige e controla a dinâmica didática. Destina-se a } \\
\text { avaliações que devem reproduzir os conhecimentos com a maior precisão possível. }\end{array}$ \\
\hline $\begin{array}{l}\text { Atividades de } \\
\text { ensino/avaliação }\end{array}$ & $\begin{array}{l}\text { Grande separação entre os objetivos e os motivos do professor e dos alunos. Eles se sentem desconectados e } \\
\text { desinteressados. O professor se sente frustrado. As demandas sociais e culturais não são atendidas pelo modelo } \\
\text { transmissivo. }\end{array}$ \\
\hline \multicolumn{2}{|l|}{ Por descobrimento } \\
\hline $\begin{array}{l}\text { Pressupostos e objetivos da } \\
\text { educação científica }\end{array}$ & $\begin{array}{l}\text { A ciência é um produto natural da mente das crianças. Ante o mesmo problema, o modo de pensar de uma } \\
\text { criança não difere do de um cientista. A realidade é descoberta aplicando o método científico. }\end{array}$ \\
\hline $\begin{array}{l}\text { Critérios para selecionar e } \\
\text { organizar o conteúdo }\end{array}$ & $\begin{array}{l}\text { Exclusivamente disciplinares, na forma de problemas que exigem uma solução através da experimentação. O } \\
\text { currículo se concentra no ensino e na aplicação do método científico. Por si só é um método de ensino. }\end{array}$ \\
\hline $\begin{array}{l}\text { Atividades de } \\
\text { ensino/avaliação }\end{array}$ & $\begin{array}{l}\text { Devem ser semelhantes às atividades de pesquisa. O papel do professor é facilitar a descoberta por parte dos } \\
\text { alunos de atividades guiadas, fazendo perguntas. A avaliação considera a maneira pela qual se alcança ao } \\
\text { conhecimento conceitual, os processos e atitudes. } \\
\text { Supõe que o objeto de pesquisa seja entendido corretamente na descoberta. }\end{array}$ \\
\hline $\begin{array}{l}\text { Atividades de } \\
\text { ensino/avaliação }\end{array}$ & $\begin{array}{l}\text { Assume-se compatibilidade entre a mente dos estudantes e a das cientistas. Os problemas cotidianos } \\
\text { geralmente não são resolvidos com a aplicação do método científico. Por si só, não leva ao uso, organização e } \\
\text { transformação do conhecimento de maneira mais ordenada e inclusiva. A motivação para descobrir é } \\
\text { alcançada e nutrida se a descoberta for bem-sucedida. }\end{array}$ \\
\hline \multicolumn{2}{|c|}{ Através de pesquisa direcionada } \\
\hline $\begin{array}{l}\text { Pressupostos e objetivos da } \\
\text { educação científica }\end{array}$ & $\begin{array}{l}\text { O aluno é colocado em um contexto semelhante ao de um cientista, acompanhado pelo professor como diretor } \\
\text { de pesquisa. } \\
\text { Não se concebe o método científico e sua aplicação como componente essencial ou principal da atividade } \\
\text { científica. Procura mudar conceitos, procedimentos e atitudes, através de um processo de construção social de } \\
\text { teorias, colocando o aluno em contextos sociais de construção de conhecimentos semelhantes aos vividos } \\
\text { pelos cientistas. } \\
\text { Ensino baseado na solução de problemas. }\end{array}$ \\
\hline $\begin{array}{l}\text { Critérios para selecionar e } \\
\text { organizar o conteúdo }\end{array}$ & $\begin{array}{l}\text { Baseado na solução de problemas que surgem da análise do conhecimento da disciplina. O conteúdo } \\
\text { selecionado não é específico, mas estruturas conceituais da ciência. }\end{array}$ \\
\hline $\begin{array}{l}\text { Atividades de } \\
\text { ensino/avaliação }\end{array}$ & $\begin{array}{l}\text { Se levanta e resolvem problemas de natureza aberta (exigem realizar pequenas investigações) de maneira } \\
\text { conjunta entre aluno e professor. O professor orienta, reforça e solicitam a reflexão e o questionamento das } \\
\text { conclusões que emergem por parte dos alunos à luz das contribuições que recebem os cientistas ao resolver } \\
\text { esses mesmos problemas. O trabalho é realizado sobre o aspecto social do processo de resolução de problemas, } \\
\text { estimulando a comunicação e a discussão entre alunos e entre eles e o professor, facilitando a explicação dos } \\
\text { procedimentos, atitudes e conceitos. A avaliação a serviço da aprendizagem, com base no trabalho diário dos } \\
\text { alunos durante a pesquisa. Eles fornecem informações para entender as causas do sucesso ou fracasso da } \\
\text { investigação. }\end{array}$ \\
\hline $\begin{array}{l}\text { Atividades de } \\
\text { ensino/avaliação }\end{array}$ & $\begin{array}{l}\text { O professor é muito exigido, o que dificulta sua aplicação geral. } \\
\text { Implica uma concepção da ciência e o ensino dela que nem é geral. No professor exige uma mudança } \\
\text { conceitual, de atitudes e procedimentos que acompanham a de seus alunos. A aprendizagem do conteúdo } \\
\text { científico não é construída sob os mesmos processos que os cientistas usam. }\end{array}$ \\
\hline
\end{tabular}

Fonte: adaptado de Chassot (2018).

Para Souza, Bastos e Angotti (2007), os professores não aplicam as abordagens de uma maneira pura, mas que o combinam, recriam e ressignificam, não tendo consciência, em muitas ocasiões, disso ou das decisões que tomam com base nessas concepções. $\mathrm{O}$ autor também defende que não existe uma estratégia didática simples que garanta sucesso no ensino de ciências naturais. Isso está relacionado ao fato de os professores frequentemente procurarem um método único que possa ser aplicado em todos os casos ou cair na rotina de repetir um modelo de prática monótono e com pouco apoio, sem renovação. 
Atualmente, autores como Geraldo (2014) incorporam novas abordagens baseadas em uma realidade educacional que requer integração e convivência dialógica das diferentes visões, bem como o surgimento de outras que proporcionam luz e flexibilidade às tarefas práticas da sala de aula.

A metodologia proposta pelo autor envolve investigação. Souza, Bastos e Angotti (2007) especificam que essa metodologia não requer o deslocamento completo ou a substituição de outras modalidades de ensino, mas pode ser incorporada através da integração de práticas conhecidas e usadas diariamente, além de outras menos conhecidas. Mencionando alguns exemplos, os experimentos são incluídos como "receitas culinárias" que requerem seguir uma série de etapas ordenadas. É importante lembrar que os mesmos devem estar acessíveis à compreensão dos alunos, permitindo que eles compreendam os fenômenos apresentados e respondam a uma pergunta genuína, não apenas que denote uma expressão de interesse.

Outra metodologia apresentada, apoiada na pedagogia que se concentra em projetos didáticos. Segundo Terrazzan e Dutra (2009, p. 46), os projetos constituem "planos focados em um processo de pesquisa em sala de aula", e realizá-los nos anos iniciais do Ensino Fundamental I "ajuda a romper com a abordagem tradicional de ensino de ciências naturais".

Vários estudos concordam com as virtudes do trabalho do projeto para desenvolver conteúdo científico, estimular a motivação e participação das crianças. Da mesma forma, contribui para o desenvolvimento das características da pesquisa, como formular hipóteses e projetar ou escolher estratégias para provar ou refutá-las e apresentar problemas.

Por outro lado, se estimulam também outros aspectos da criança como habilidades as cognitivas, psicomotoras, socioafetivas, entre outros.

\subsection{Obstáculos ao ensino das Ciências da Natureza}

Vários estudos coincidem com Terrazzan e Dutra (2009) na descrição dos obstáculos que os professores argumentam ao ensinar Ciências da Natureza; dentre eles, o excesso de conteúdo acadêmico das escolas e preparação insuficiente dos professores, dados que coincidem com os coletados em campo.

Aqui geralmente expõem-se os hábitos de sempre: que não há boa formação, que o conteúdo é interminável e devemos correr, que não temos um bom laboratório. Todas as questões que merecem atenção, "mas que nos desviam do nosso verdadeiro papel de professor de ciências: o de acompanhar nossos alunos no caminho da descoberta" (Terrazan; Dutra, 2009, p. 98).

Quanto ao excesso de conteúdo escolar, o olhar é direcionado para os programas oficiais. Delizoicov, Angotti e Pernambuco (2011) enfocam a dicotomia entre o professor que sente a responsabilidade de cumprir o programa linearmente e em todos os seus termos e aquele que toma a liberdade de adaptá-lo à realidade contextual:

Uma discussão que não é realizada em nosso ambiente é se os programas devem apresentar uma interpretação única do conteúdo e de suas formas de transmissão ou, se, pelo contrário, transmite uma proposta curricular adequada às condições específicas de uma escola e de um grupo específico de professores e alunos. Para os autores do parágrafo acima, a ausência dessa discussão reforça a predominância de uma visão unitária dos programas e, inclusive, que se considere que a responsabilidade do professor é cumpri-los completamente.

Além disso, Chassot (2018) destaca a importância da seleção dos conteúdos, cada vez são mais os conhecimentos que competem por um lugar no currículo chegou o momento de reconhecer que temos a responsabilidade de selecionar algumas "histórias" importantes das quais a ciência oferece e fornece um olhar sobre a construção do conhecimento científico e seu poder explicativo.

Outro obstáculo está concentrado no tempo dedicado concedido ao ensino de Ciências da Natureza. De acordo com Terrazzan e Dutra (2009), é necessária uma carga de tempo maior para as ciências naturais nos novos currículos e na atualização de seus conteúdos. Também no projeto mencionado, enfatiza-se a falta de tratamento dessas áreas desde tenra idade. Esse trabalho deficiente nas ciências naturais parece ser atribuído à escassa formação de professores desses níveis nas disciplinas 
científicas. Isso determina que, em geral, os professores de educação básica passam mais tempo trabalhando em outras áreas do conhecimento em detrimento da área científica.

\subsection{O ensino de Ciências da Natureza nos anos iniciais do Ensino Fundamental}

O ensino de Ciências da Natureza sofreu mudanças importantes nos últimos anos; os mesmos foram gerados em grande parte graças às contribuições teóricas de vários autores como Ausubel e Piaget. Esses autores argumentam que as crianças pequenas têm a capacidade de entender o conteúdo relacionado à ciência, caso se adapte ao seu desenvolvimento.

Segundo Marandino (2009), existem muitas pesquisas que mostram que aquelas crianças que trabalham na área das ciências desde a tenra idade, alcançam progressos cognitivos mais rapidamente e os mesmos são claramente evidenciados.

Da mesma forma, é destacada a importância da alfabetização científica no estágio de 3 a 6 anos como um motor para um interesse subsequente na cultura científica: “O estágio de 3 a 6 anos deve ser o onde são forjadas as primeiras bases para o desenvolvimento progressivo dessa competência, concentrando a atenção naqueles aspectos ou situações mais próximas e palpáveis das crianças" (Chassot, 2018, p. 87).

Partindo de uma concepção de ensino de ciências que promova a produção ou construção da mesma com os outros e não a transferência de conhecimentos, percebe-se a importância de se realizar algumas especificações sobre as particularidades do nível inicial de educação a esse respeito.

Ensinar nesse nível envolve acompanhar a criança na construção dos significados culturais que carregam os objetos, as ações, os gestos, os modos de agir, as festividades, os costumes entre outros. Também envolve oferecer experiências de observação, exploração e experimentação para expandir e enriquecer o conhecimento das características do mundo físico e natural. Tendo em vista essas particularidades que o ensino possui no nível mencionado, é importante quando procuramos compreender as estratégias, os recursos e os tempos de ensino.

Uma das peculiaridades dos anos iniciais é a relevância do jogo como um mecanismo do ponto de vista didático. Segundo Chassot (2018), o ensino de ciências no nível inicial deve considerar o desenvolvimento evolutivo da criança, planejando uma variedade de atividades às quais se relaciona com a "pluralidade metodológica", com base em "interesses e particularidades individuais dos quais aprendem, colocando-os em um lugar central como construtores de seu próprio conhecimento" (Chassot, 2018, p. 78). Também destaca a importância de considerar o ambiente em que o processo de ensino e aprendizagem ocorrerá, adaptando-o e agregando-o à flexibilidade do cronograma.

Do mesmo modo, Perrenoud (2007) ressalta-se a concepção de ensino, ensinar inclui olhar para o horizonte das crianças que deve formar de acordo com conceitos e critérios pedagógicos para fortalecer seu desenvolvimento integral desde as primeiras idades, recorrendo ao seu cotidiano para realizar exercícios de ciências, em um mundo que não é indiferente às suas curiosidades e fantasias.

Nesta linha, encontramos Lakomy (2014, p.125), que vincula a curiosidade com o aprendizado:

A literatura mostra a existência de uma relação positiva entre curiosidade e aprendizado, que deve ser considerado em processos de formação de crianças, pois, promovendo o comportamento curioso em tenra idade está desenvolvendo uma disposição que pode permanecer por toda a vida.

Por outro lado, Cachapuz et al (2011) desenvolve as habilidades que seriam convenientes estimular ao ensinar ciências nos anos iniciais do Ensino Fundamental e enfatizar a atividade prática, com propósitos diferentes. São categorizados pelo autor como habilidades básicas (uso de material científico ou de laboratório: microscópio, termômetro, entre outros); observação; demonstração; explorações e pesquisas.

O autor alude que as atividades práticas devem ser complementadas pelo pensamento, o diálogo e a imaginação, bem como o papel fundamental da linguagem na aprendizagem, manifestados na formulação de questões que apoiam a investigação. 
Além disso, acrescenta as condições sob as quais o as crianças aprendem melhor. Isso inclui o desenvolvimento de atividades em um contexto significativo, relacionado às suas experiências e à vida cotidiana.

Começando pelas ideias das crianças e pelas perguntas que se formulam, usando histórias familiares, são alguns dos caminhos para garantir não apenas que as atividades sejam significativas, mas também as conexões que estão fundamentadas entre a ciência e o cotidiano das crianças. Na mesma linha, se encontra o contributo de Lakomy (2014, p. 68): "A partir dessas situações, que ocorrem no cotidiano dos alunos, que são uma fonte de motivação na maioria dos casos, nós, como professores, devemos facilitar a abordagem dos diferentes fenômenos".

Além das habilidades apontadas por Lakomy (2014) explica os conteúdos procedimentais, que se estimulam e treinam ao trabalhar as ciências naturais de maneira abrangente, visando entender como o conhecimento científico é construído, como a ciência e os cientistas interrogam a natureza. Esses autores dão ao conteúdo processual o nome de "habilidades de processos". As mesmas são a observação, a classificação, a medição, a comunicação, a estimativa e previsão e a inferência. As mesmas acrescentam a seriação e introduz uma contribuição considerável. Argumenta que, ao usar essas habilidades como uma ação educativa em sala de aula, leva a criança à experimentação. Desta forma, seu desenvolvimento integral é favorecido, lançando as bases para promover uma atitude positiva em relação a aprendizagem das ciências.

$\mathrm{O}$ autor considera que a curiosidade que a criança traz consigo precisa de orientação por meio de observação e diretrizes organizacionais, para que o aprendizado seja enriquecido pelas habilidades postas em ação.

Por outro lado, de acordo com Geraldo (2014, p. 122), o ensino do conhecimento e sobre a ciência representa um desafio para as instituições de ensino, "não apenas pelo dever de ser, mas por elas experimentarem o desejo de saber além da utilidade do conhecimento, promovendo a curiosidade que a criança já traz".

O autor considera que é conveniente subestimar a capacidade hipotético-dedutiva das crianças em comparação com adolescentes, desde que esta se realize em tarefas que possam ser entendidas pelos primeiros e com aqueles que tenham alguma experiência. Pelo contrário, parece que as crianças possuem desde cedo capacidades de aplicar procedimentos próximos à metodologia científica.

Geraldo (2014) explica que a criança na fase inicial pareceria não apenas ser capaz de aprender o conteúdo científico, se apresentado em um nível adequado de formulação, mas em tenra idade, seu interesse pela ciência (entendido como curiosidade em conhecer o mundo à sua volta, natureza, meio ambiente, seu próprio corpo) parece ser maior ao apresentado pela mesma criança na fase escolar. Mais uma vez, é evidente a oportunidade que esse nível educacional representa na estimulação do espírito científico, dos procedimentos que a ciência envolve, dos desafios e características de um conhecimento dinâmico, esclarecedor, mas aberto a questionamentos e revisões contínuas.

A criança pequena pode acessar o conhecimento científico das ciências ao cientificar sua atividade em relação ao mundo físico, adaptando os fenômenos do mundo natural ao estágio evolutivo da criança, próximo às competências e habilidades cognitivas que possui. Para "cientificar" é necessária a ajuda do professor, que transfere fenômenos do mundo físico para o mundo simbólico.

\section{O Ensino de Ciências: O Quê e como Ensinar Ciências nos Anos Iniciais}

Após as rápidas mudanças sociais, culturais, científicas e tecnológicas que estão ocorrendo em nossa sociedade atual, é necessário adaptar o ensino oficial que é realizado nas escolas, integrando novos conhecimentos, procedimentos, atitudes, habilidades ou competências científicas no currículo dos diferentes estágios educacionais.

De acordo com Chassot (2018, p. 46) é possível definir ciência como o "conjunto de conhecimentos obtidos através da observação e do raciocínio, sistematicamente estruturados e a partir dos quais princípios e leis gerais são produzidos com capacidade preditiva e verificável experimentalmente". 
Em outra definição de ciência podemos entender que, Ciência representa todo o conhecimento adquirido através do estudo, pesquisa ou da prática, baseado em princípios certos. Esta palavra segundo Chassot (2018), deriva do latim scientia, cujo significado é "conhecimento" ou "saber". Em geral, a ciência, que é muito ampla, comporta vários conjuntos de saberes nos quais são elaboradas as suas teorias baseadas nos seus próprios métodos e pesquisas científicas.

Levando em consideração essas duas definições a partir da Educação Infantil, é possível se questionar como se deve ensinar ciências e que ciência ensinar.

No currículo oficial da BNCC (2017), a importância da educação científica é destacada desde a primeira infância. Portanto, é preciso fazer com que os alunos adquiram e desenvolvam certas habilidades científicas que lhes permitam conhecer seu ambiente imediato, compreendê-lo a partir da observação de fenômenos, aprender certos conceitos e princípios simples e se acostumar a trabalhar em sala de aula através de uma metodologia de a investigação e experimentação das coisas ou objetos que os rodeiam, em suma, dão início à sua alfabetização científica.

É amplamente demonstrado que desde que nascemos, queremos saber, precisamos entender; perguntamo-nos como funcionam as coisas que vemos ao nosso redor, o porquê do que vemos. As crianças fazem perguntas a si mesmas e, com base em suas próprias observações, ações e pensamentos, procuram encontrar as respostas e tirar suas próprias conclusões. Facilitando e promovendo esses processos em sala de aula, os colocamos no caminho de seu desenvolvimento integral como pessoas e de sua alfabetização científica.

A aprendizagem científica é um processo que surge de uma curiosidade natural por conhecer e compreender os fenômenos que nos rodeiam. O homem é programado para a curiosidade, e é essa curiosidade o elemento essencial de toda investigação científica. A curiosidade é o que leva as crianças menos impulsivas a observar atentamente e a fazer experiências espontaneamente, esquecendo a timidez e apostando na exploração dos espaços e objetos que as rodeiam e que lhes interessam (Morais, 1998).

Portanto, é possível considerar de grande interesse para os professores dos anos iniciais conhecerem os aspectos a levar em consideração ao abordar o ensino de ciências na fase infantil, bem como as indicações que aparecem em artigos de pesquisa e bibliografia da área.

Assim sendo, necessário se faz proceder a uma revisão tanto dos aspectos que estão incluídos na legislação em vigor sobre o ensino de ciências na Educação Infantil quanto na bibliografia do campo da didática das ciências.

Na BNCC (2017), podem-se encontrar muitos aspectos didáticos que se relacionam com os conteúdos trabalhados na ciência. Especificamente, em duas das áreas de experiência em que se divide o currículo infantil, na área de autoconhecimento e autonomia pessoal e na área de conhecimento do meio ambiente. Dentro destas duas áreas está inserido um conjunto de conteúdos e objetivos, que visam estabelecer critérios que orientem o processo educativo e que ajudem a promover o desenvolvimento de uma aprendizagem significativa nos alunos. Esses critérios permitem uma orientação positiva sobre o que e como crianças devem aprender na ciência.

Se os professores se perguntarem: como e quais ciências ensinar na Educação Infantil? O desafio está em superar as próprias crenças sobre o que ensinar e como ensinar, posicionadas em uma noção fechada de ciência que engloba um grande número de conceitos e conteúdos não textualizados e pouco relacionados. Estes conteúdos requerem um elevado nível de abstração e memorização, capacidades que num corpo discente de 0 a 6 anos, dado o nível evolutivo em que se encontram, não atingiu e, portanto, não há aprendizagem significativa sendo logo esquecida. Mas isso não deve ser uma desculpa, mas sim um desafio, e não deve ser um motivo para não lidar com o conteúdo de ciências e que os alunos comecem a desenvolver certas habilidades científicas; pois através de diferentes fenômenos do cotidiano, ajudam a introduzir conceitos e princípios científicos simples, que por meio de uma metodologia adequada de investigação, manipulação e experimentação, é possível levar o conhecimento da ciência para a sala de aula das crianças (Morais, 1998). 
Num estudo recente realizado por Fabri e Silveira (2013), as formações científicas sugeridas pelos Parâmetros Curriculares Nacionais, mais conhecidos como PCNs, indicam que os resultados recomendaram que as ciências escolares sugeridas no currículo oficial da infância estão em sintonia, em sua maior parte, com as tendências atuais da didática das ciências e que apresenta uma proposta mais completa e profunda do que os PCNs.

Quando o assunto é o que ensinar em ciência nos anos iniciais, considera-se importante promover o acesso a um conhecimento significativo da realidade, começando de alguma forma com o ambiente natural e social mais próximo. Portanto, os conteúdos a serem ministrados:

- Devem estar relacionados à sua vida cotidiana.

- Devem facilitar as ações e interações com fenômenos e objetos materiais próximos, conhecidos, pois isso favorece a construção de significados, a aquisição de habilidades e o desenvolvimento de atitudes.

- Devem permitir que o professor promova as atividades das crianças, tanto físicas como mentais, e a sua interação com os objetos, com o ambiente, com os seus pares e com os adultos.

- Na seleção dos conteúdos, será necessário levar em consideração as características e capacidades dos alunos, seu ritmo de desenvolvimento e aprendizagem, e propor uma grande variedade de atividades, organizações e intervenções que lhes permitam progredir.

- Devem ser interessantes e motivadores para as crianças, de modo que estimule seu envolvimento e gosto pela descoberta, pela indagação, pela experimentação, o que não restringe sua grande curiosidade pelo ambiente que as incentiva a explorar e tentar compreender.

- Aprender ciências implica modificar e ajustar as aprendizagens adquiridas desde o nascimento, portanto, devem favorecer a aprendizagem significativa.

- A partir de temas relacionados ao cotidiano, as crianças aprendem a interpretar os fatos e desenvolver modelos interpretativos do que estão vivenciando.

- Toda prática científica inclui três elementos principais: uma fase criativa individual que parte do conhecimento comumente aceito pela comunidade; uma fase experimental, onde são utilizados procedimentos aceitos e validados por uma comunidade; e uma fase de análise e comunicação dos resultados adotando um vocabulário e formas de exposição aprovadas pela comunidade (Chassot, 2018, p. 132-133).

Assim, numa primeira fase será necessário dar às crianças a oportunidade de pensar criativamente, uma vez que infelizmente, a obsessão dos educadores em ensinar conhecimentos científicos e eliminar erros muitas vezes provoca uma rejeição do pensamento especulativo das crianças, promovendo uma visão da ciência caracterizada pela rigidez e intolerância (Chassot, 2018).

Ambos Fabri e Silveira (2013) e Chassot (2018), fazem uma crítica coincidente de "aprendizagem por descoberta incidental e autônoma" (Fabri; Silveira, 2013, p. 51); pois, "é sobre aprender ciências, não (re) fazer ciência (Chassot, 2018, p. $65) "$.

Segundo Azevedo (2016), nas escolas de hoje, não se ensina a pensar ou trabalhar cientificamente; só se ensina a usar o vocabulário científico mecanicamente.

As ciências que se ensinam devem servir às novas gerações como método de fruição, observando o mundo à sua volta e aprendendo com ele e com tudo o que ela proporciona, pois, a ciência permite compreender as mudanças que ocorrem no planeta, tantos as naturais e produzidas pelo ser humano e ajuda a atuar de forma consistente em prol da sustentabilidade social. 
Pode-se transmitir aos alunos apenas diretrizes para agir, mas se o que se quer é que eles sejam capazes de tomar decisões de forma independente e fornecer novas soluções para os problemas, será necessário que eles aprendam a construir modelos teóricos da ciência.

Num estudo de Cachapuz (2011), para 86\% do corpo docente ainda são prioritários oferecer informações básicas úteis para que os alunos conheçam e utilizem o vocabulário específico das ciências e desenvolvam leituras compreensivas de textos científicos. Considera de grande importância o desenvolvimento em aula de conceitos e teorias que permitam ao aluno conhecer o próprio corpo, o ambiente natural e a interação entre os seres humanos, além de proporcionar-lhes um grande conhecimento sobre o assunto para que possam continuar seus estudos mais tarde. Do lado oposto, $17 \%$ dos professores consideram que esta não é uma tarefa prioritária para o exercício da aula de ciências e procuram ideias mais inovadoras para promover a aprendizagem e o ensino das ciências, mas infelizmente este percentual ainda é muito menor do que o grande número de professores que optam por um ensino tradicional de aprendizagem mecânica que não é muito útil para um ensino significativo.

Pode-se concluir, assim, que apenas metade dos professores procura acomodar em suas aulas de ciências os problemas científico-tecnológicos, ambientais ou de saúde que compõem a sociedade, a fim de formar cidadãos informados sobre o que está acontecendo no mundo que os cerca. Do restante, percebe-se que cerca de 30\% não procuram desenvolver uma ciência contextualizada e cerca de $20 \%$ permanecem em posições intermediárias entre as duas partes.

Ainda assim, é possível constatar que na grande maioria dos casos, o livro didático ou os diversos materiais das editoras, bem como o currículo prescritivo ocupam o lugar central no desenvolvimento de uma aula, deixando como aspecto secundário outras formas de ensino como a utilização do ambiente como ferramenta de trabalho, as opiniões e sugestões dos alunos, bem como os problemas atuais que se veem diariamente em todos os meios de comunicação e a dimensão prática destes nas aulas (Cachapuz, 2011).

Quando o assunto é como ensinar ciências nos anos iniciais, vale considerar as palavras de Hazen e Trefil (2010) que afirmam que uma criança para aprender ciências deve agir de acordo com o conceito, o que significa que a criança está fisicamente envolvida na realização da atividade e pode ver e verificar o resultado da realização disso através da exploração e manipulação.

As crianças desde o nascimento já são "investigadoras", nascem com aquela sensação de explorar e manipular tudo o que lhes chama a atenção. O professor deve promover esta atividade nas crianças.

À medida que as crianças investigam e exploram em seu ambiente mais próximo, no mundo físico, elas adquirem novos conhecimentos que se somam aos conhecimentos anteriores que já possuíam. Quanto mais elas o adquirem, mais fácil elas terão para desenvolver novos conceitos (Cachapuz, 2011).

Por este motivo, considera-se a importância de saber organizar uma aula de forma a despertar o interesse e a motivação das crianças e para isso é necessário conhecer os temas científicos, a metodologia adequada, os recursos disponíveis e como organizar a sala de aula, atividades e participação dos alunos.

Atualmente, pais e professores concordam que o ensino na Educação Infantil tende a se concentrar principalmente em certas habilidades, como alfabetização e o início da matemática, deixando de lado o ensino de ciências por meio do uso de a metodologia de investigação e o desenvolvimento de experiências para a investigação do meio em que vivem, aspectos que também fazem parte do currículo infantil (Cachapuz, 2011).

Percebe-se, então, que os professores devem estar atentos aos conteúdos que são trabalhados nos anos iniciais, pois é amplamente comprovado que as crianças não aprendem quando se oferece algo que não lhes interessa, melhorando os resultados da aprendizagem, quando são elas que decidem quais temas discutir, quando se leva em consideração suas motivações ou interesses e os professores assumem estas questões com um papel mais orientador para que encontrem soluções para as questões que lhe são colocadas ou para compreender alguns fenômenos do quotidiano, ou sobre o funcionamento das coisas que observam 
no seu quotidiano. Por isso, o professor deve estar atento e aproveitar esta oportunidade e aproveitar ao máximo essa curiosidade natural que o aluno demonstra.

Por outro lado, vários autores como Auler (2003) referem-se ao fato de que o ensino de ciências na Educação Infantil não deve ser tratado como uma disciplina isolada das demais, pois deveria estar presente em cada uma das aprendizagens que a criança deve adquirir, seja ao trabalhar aspectos da linguagem, matemática, atividades artísticas, etc.

Atualmente, se considera a globalização um elemento essencial da Educação Infantil. Este princípio globalizante visa um ensino onde, através de uma série de procedimentos, todas as capacidades dos alunos sejam ativadas. Para isso, o meio ambiente será tomado como o principal centro de interesse, uma vez que desta forma a criança pode aplicar proveitosamente esses aprendizados em diferentes contextos da vida real.

Nesse sentido, Auler (2003) destaca que a ciência é tida como elemento fundamental a ser inserida nessa perspectiva globalizante que envolve o processo de ensino-aprendizagem. Para isso, é necessário incluí-las no processo de ensino por meio de diversas atividades que possibilitem a aprendizagem ativa dos alunos, onde possam indagar, explorar, formular hipóteses e, em geral, compreender o mundo em que vivem.

É importante que o professor dê apoio emocional aos alunos para que se sintam valiosos, importantes e capazes no desenvolvimento das atividades e que sejam recompensados pelo seu trabalho e pelo seu comportamento ao trabalhar o conteúdo.

Na fase da Educação Infantil, não é aconselhável manter um ensino formal de conteúdos de ciências, é melhor estimular sua curiosidade por fenômenos naturais simples, enriquecendo seus conhecimentos com o estímulo de atitudes, procedimentos, noções positivas e com um vocabulário específico que permitir uma melhor compreensão e ação sobre o ambiente natural a partir do conhecimento das crianças (Auler, 2003).

Uma forma de organizar o currículo para que isso seja possível é trabalhar com unidades temáticas amplas e abertas ou através de projetos, para que os alunos possam escolher e planejar os seus próprios temas de investigação com a participação do docente e desta forma a sua motivação será superior. Uma aprendizagem por projetos, com uma abordagem integrada e globalizante do currículo (Cachapuz, 2011).

Segundo Sasseron (2008), para que os projetos de trabalho sejam verdadeiramente educacionais, eles devem satisfazer certas condições: que despertem grande interesse nas crianças; que incluam situações de aprendizagem relevantes que permitam o desenvolvimento das habilidades das crianças, que sejam agradáveis, divertidas e motivadoras; e que despertem a curiosidade das crianças, ajudando-as a ativar os seus mecanismos de investigação e exploração, tanto pessoal como coletivamente.

Com isso, pode-se construir um conhecimento em que alunos e professores dão sentido conjunto aos temas, a partir de suas respectivas experiências. Pois, como diz Sasseron (2008, p. 50): “O ser humano aprende fazendo".

A experimentação deve ser uma oportunidade, não uma obrigação. Na bibliografia, ou no mundo digital (páginas web, Blogs, etc.) muitas experiências científicas aparecem como "experimentos", que não o são, muitas são experiências fechadas, descritivas, do "tipo receita", onde os alunos nada têm para fazer. Em outras palavras, eles não podem participar nem têm conhecimento prévio de que podem se relacionar com o que estão observando. Chassot (2018) apresenta uma lista do que não é experimentar e lembra que cada criança deve ter liberdade para experimentar como quiser ou sobre o que quiser. Segundo este autor: experimentar não é perceber ou sentir qualquer sensação, não é seguir instruções fixas, não é um truque de mágica, não é fazer trabalho manual, não é trapacear com a realidade, não é apenas manipular, não é promover atos de fé, não é uma atividade isolada, não é um procedimento de demonstração, nem é uma atividade solitária, sem emoções associadas.

Chassot (2018, p. 145) estabelece uma série de condições que devem ser atendidas e propõe formas para trabalhar o aprendizado de ciências nos anos iniciais:

- Dar a cada criança a oportunidade de participar do experimento com ênfase especial no uso dos sentidos. 
- Fazer tudo de forma que não cause medo, sempre que possível.

- Ser paciente com as crianças.

- Deixar que as crianças controlem o tempo que leva para realizar um experimento.

- Sempre fazer perguntas abertas.

- Dar às crianças tempo suficiente para responder às perguntas.

- Não esperar reações ou respostas "padrão" das crianças.

- Aceitar sempre respostas divergentes.

- Certificar-se de que a observação seja incentivada.

- Procurar sempre formas de expandir a atividade.

É importante que as atividades realizadas em sala de aula não sejam impostas pelos professores, mas sim que os alunos possam decidir sobre elas, levando-os a interagir com outras crianças para fortalecer as experiências por meio de trocas e socialização de ações e ideias, levando-os a tomar decisões e respeitar as dos outros.

O conhecimento é algo pessoal, mas se enriquece quando as experiências são compartilhadas e trabalhadas em grupo. Chassot (2018) estabeleceu cinco condições para que isso fosse direcionado a uma forma de elaboração de uma representação simbólica:

- O uso de palavras como um convite para formar conceitos.

- A possibilidade de diálogo entre a criança e o adulto.

- A importância da escola como inovação.

- Desenvolvimento dentro de uma cultura de conceitos "científicos".

- O possível conflito entre modos de representação.

\section{Conclusão}

Mesmo se colocarmos de lado o que a ciência diz sobre a capacidade cognitiva da criança sobre a importância dos primeiros anos na formação das conexões neuronais, não podemos evitar, ao olhar para ela desde pequena, perceber o que a diverte, com que brinca, o que lhe interessa no recreio.

O interesse pelas Ciências da Natureza faz parte da vida da criança desde pequena, pelo que deve ser considerado um desafio, mas ao mesmo tempo uma oportunidade, para que os professores possam ligar-se a este interesse e mover juntos a motivação para a aprendizagem em todas as suas dimensões, estimulando a curiosidade da criança e transformando-a em uma infinidade de coisas.

O fato de identificar o tempo dedicado às ciências naturais na sala de aula e os fatores que influenciam sua insuficiência podem proporcionar a todos os atores institucionais a oportunidade de revisar os tempos, prioridades e objetivos educacionais que poderiam redefinir-se, concentrando-se na dedicação às ciências naturais e aos motivos que influenciam neles. Esses motivos, quando explicitados, oferecem a possibilidade de identificá-los e visualizá-los, podendo intervir neles.

Identificar os pontos fortes do ensino nas equipes de trabalho, em termos de reprodução de estratégias e gerenciamento de recursos, pode não apenas ressignificar o valor do professor como uma figura crucial no ensino (em termos de criatividade e capacidade de abordar o conteúdo, usando recursos de maneira diferente), mas também capitalizar esse potencial como uma possível referência para o restante da equipe de ensino. Também é relevante para esse fim, identificar o grau de adesão dos professores ao projeto institucional ou a suas linhas de trabalho, por meio das estratégias que utilizam, das habilidades que promovem e da gestão que fazem de tempo e recursos. 


\section{Referências}

Azevedo, L. B. S (2016). Ensino de Ciências por Investigação nos Anos Iniciais do Ensino Fundamental: estudos dos conceitos básicos de eletricidade para a promoção da alfabetização científica. 142 f. Dissertação (Mestrado Profissional em Ensino de Ciências e Matemática) - Universidade Federal de Alagoas, Maceió.

Auler, D. (2003). Alfabetização científico-tecnológica: um novo “paradigma”? Ensaio: Pesquisa em Educação em Ciências, 5 (1). http://www.portal.fae.ufmg.br/seer/index.php/ensaio/article/viewFile/60/97

Brasil. Base Nacional Comum Curricular (BNCC). (2019). Ministro da Educação. Secretaria de Educação Básica. Brasília. http://basenacionalcomum.mec.gov.br/images/BNCC_EI_EF_110518_versaofinal_site.pdf

Cachapuz, A. F, et al. (Org.). (2011). A necessária renovação do ensino das ciências. (3a ed.) Cortez.

Chassot, A. (2018). Alfabetização científica: questões e desafios para a educação. (8a ed.) Ed. Unijuí,

Demo, P. (2014). Pesquisa e construção do conhecimento: metodologia científica no caminho de Habermas. Tempo Brasileiro.

Delizoicov, D. \& Angotti, J. A. \& Pernambuco, M. M. C. A. (2011). Metodologia do ensino de ciências. Cortez.

Fabri, F. \& Silveira, R. M. C. F. O. (2013). O ensino de Ciências nos anos iniciais do ensino fundamental sob a ótica CTS: uma proposta de trabalho diante dos artefatos tecnológicos que norteiam o cotidiano dos alunos. Investigações em Ensino de Ciências. 18 (1). http://www.if.ufrgs.br/ienci/artigos/Artigo_ID321/v18_n1_a2013.pdf

Geraldo, A. C. H. (2014). Didática de Ciências Naturais: na perspectiva histórico-crítica. (2a ed.) Coleção formação de professores. Autores Associados.

Hazen, R. M. \& Trefil, J. (2010). Alfabetização Científica: O que é, por que é importante e por que faz falta. Saber Ciência. (6a ed.) Cultura Editores Associados.

Lakimy, A. M. (2014). Teorias cognitivas da aprendizagem. Série Construção Histórica da Educação.

Marandino, M. (2009). Ensino de Biologia: Histórias e práticas em diferentes espaços educativos. Cortez.

Morais, R. (1998). Ciências para Séries Iniciais e alfabetização. Sagra DC Luzzatto.

Perrenoud, P. (2007). Construir as Competências Desde a Escola. Artmed.

Ribeiro, M. L. S. (2011). História da educação brasileira. Vozes.

Sasseron, L. H. (2008). Alfabetização Científica no Ensino Fundamental: Estrutura e Indicadores deste processo em sala de aula. 265f. Tese (Doutorado em Educação). USP - Faculdade de Educação.

Silva, T. G. (2011). Estudo sobre a relação da cognição e emoção na construção do saber científico nos anos iniciais do Ensino Fundamental. Universidade do Estado do Amazonas.

Souza, C. A. \& Bastos, F. P. \& Angotti, J. A. P. (2007). Cultura Científico-Tecnológico na Educação Básica. Ensaio. Pesquisa em Educação em Ciências, 9 (1).

Terrazzan, E. A. \& Dutra, E. F. (2009). Formação identitária de professores para a educação em ciências na Educação Básica. VII Encontro Nacional de Pesquisa em Educação em Ciências.

Unesco. (2008). Educação de qualidade para todos: um assunto de direitos humanos. Organização das Nações Unidas para a Educação, a Ciência e a Cultura. 2. ed. Brasília :UNESCO, OREALC. 〈https://unesdoc.unesco.org/ark:/48223/pf0000150585>

Unesco. (2003). A ciência para o século XXI: uma nova visão e uma base de ação. UNESCO, ABIPTI.

htt p://www.dominiopublico.gov.br/download/texto/ue000207.pdf 